\title{
Mini Review : SeDem System as a Tool to Characterize Excipients in Solid Dosage Form
}

\author{
Iyan Sopyan*, Rizka Guntina Khairunisa
}

Department of Pharmaceutics and Technology of Pharmacy, Faculty of Pharmacy Universitas Padjadjaran, Jl. Raya Bandung Sumedang Km.21, Sumedang, Indonesia 45363

Received: 13 Feb 2021, Revised: 8 March 2021, Accepted: 16 March 2021, Published: 20 March 2021

\begin{abstract}
SeDem System is a new system that can be applied in solid dosage form preformulation studies of medicines. It has parameters to evaluate critical quality attributes of materials that have an impact on final drug product's quality. SeDeM studies could be used as a method for identifying the best excipient and calculating the maximum amount of excipient required for formulation. SeDeM method can providing formulation with the lowest amount of excipients as it combines the Active Pharmaceutical Ingredients (API) with only one excipient and the standard formula of lubricants, thus avoiding the used of unnecessary excipients, such as diluents, binders and agglutinants. The information given by the SeDeM system contributes to a quality by drug design development.
\end{abstract}

Keywords: SeDeM System, Excipients

\section{Introduction}

In recent years, several technologies are available to produce solid dosage forms. One is the direct compression method. This method offers a number of advantages such as fewer manufacturing steps, eliminating heat and humidity processes, simplified validation, and improving drug stability. The things that need to be addressed that can determine the success of the direct printing process are the characteristics of mixed pre-compression powders, such as flowability and compressibility. In most cases, excipients have higher concentrations than active pharmaceutical ingredients (APIs). As a result, excipients contribute critically to the processing, stability, safety and performance of drugs. The quality and effectiveness of the drug depends largely on how the excipient works.
This requires appropriate flowability, adequate compactibility, a homogeneous mixing process without drug segregation, good physical and chemical stability including chemical drug compatibility. Most of the available excipients are now less well and less suitable for achieving the desired set of functions 1 .

Therefore, research to identify the most suitable excipients and calculate the exact number of excipients required for direct compression of the API is indispensable. SeDeM has many advantages, such as identifying the best excipient, creating a formulation requiring the lowest excipient, minimizing the variation of the type of excipients required in the formula so as to streamline the excipients used, such as diluents, binders and agglutins. the quality of SeDem is governed by ICH (International Harmonization Conference) Q8 2. 


\section{SeDeM System}

$\mathrm{SeDeM}$ is a system that is used to select the excipients used for the delivery of solid dosage forms for several solid parameters3. SeDeM is a new system for preformulation and excipient formulation studies for the manufacture of drugs, especially in solid dosage forms. This existing system is an innovative new tool that the concept of Quality by Design is regulated by ICH Q8. This system gives information related to the excipient can be forged directly or not based on the existing parameters 4 .

$\mathrm{SeDeM}$ is a process that can be used to determine the reproduction capabilities of APIs and Excipients. In addition, it can be used as a guide to incorporate less-compressed drugs with suitable materials followed by SeDeM can be used to determine a bad API latch 5 .

\section{SeDeM Parameters}

There are 12 parameters in SeDem system to be identified : bulk density (Da), interparticle porosity (Ie), particle size (\%Pf), Carr index (IC), cohesion index (Icd), Hausner ratio (IH), angle of repose (a), tapped density (Dc), flowability (tn), loss on drying (\%LoD), hygroscopicity $(\% \mathrm{H})$ and homogeneity index (Iq). Validated experimental methods and processes determine these parameters for fitting into SeDeM diagram method and analyzed to discover the suitability of the powder for direct compression. Therefore, SeDeM diagram method could be described as a mathematical and graphical representation of powder characteristic parameters for discovering direct compression suitability of various API and excipients 6, 7.

Angle of Repose

Break angle (h). The rest angle of a powder solid is determined by the funnel method. The weighted solid powder is inserted into the funnel and then knocked. Measured the height of the powder that fell so that the end of the funnel fitted with the top of the powder. The powder flows freely down through the funnel. After which the powder diameter is measured and measured also angle istanyah according to the formula:

$$
\tan \theta=\mathrm{h} / \mathrm{r},
$$

where $\mathrm{h}$ is the height and $\mathrm{r}$ is the radius 8 .

Bulk density and tapped density

Mass density. Both bulk density (LBD) and bulk density (TBD) density are determined. The powder of a preparation inserted into a measuring cup is attached to a device and shakes its purpose to prevent clots from occurring. then determined and calculated the difference of initial volume and final volume. The tap continues until no volume change is recorded. LBD and TBD are calculated.

$\mathrm{LBD}=$ Powder weight $/$ packing volume

$\mathrm{TBD}=$ Powder weight $/$ volume tapped packing 8 .

\section{Compressibility index and Hausner's ratio}

This following formula used to determine the compressibility index of granules:

Carr's compressibility index (Carr's index)

$(\mathrm{IC} \%)=[(\mathrm{TBD}-\mathrm{LBD}) \times 100] / \mathrm{TBD}$

Hausner's ratio $=(\mathrm{IH})$ Tapped density/Bulk density

Inter-particle porosity

The powder porosity of the drug is measured using the following formula:

$\mathrm{Ie}=\mathrm{Dc}-\mathrm{Da} / \mathrm{Dc} X \mathrm{Da}$

Carr index (IC \%)

It computed from Da and Dc using this equation :

$\mathrm{IC}=(\mathrm{Dc}-\mathrm{Da} / \mathrm{Dc}) \times 100$

Cohesion index (Icd)

The cohesion index is determined by directly printing the drug powder using the enteric press. After that, the hardness of the tablet is determined and the mean hardness is calculated 9. 


\section{Flow ability}

The flow rate that suitable with the method determined as the time for a fixed amount of powder to flow through the glass tunnel with
$0.85 \mathrm{~cm}$ orifice diameter. It was expressed in seconds and tenths of a second per 100 grams of sample. The mean value of three determinations always being taken 9 .

Table 1: SeDeM System For Pharmaceutical Excipients

\begin{tabular}{|lcccccc}
\hline No & Parameter & $\begin{array}{c}\text { Lactose } \\
\text { Anhydrous }\end{array}$ & $\begin{array}{c}\text { Lactose } \\
\text { Monohydrate9 }\end{array}$ & $\begin{array}{c}\text { Lactose } \\
\text { SD }^{\mathbf{9}}\end{array}$ & $\begin{array}{c}\text { Microcrystalline } \\
\text { Cellulose }^{\mathbf{3 3}}\end{array}$ & $\begin{array}{c}\text { Maize } \\
\text { Starch }^{\mathbf{1 3}}\end{array}$ \\
\hline $\mathbf{1}$ & $\begin{array}{c}\text { Parametric } \\
\text { index (IP) }\end{array}$ & 0.50 & 0.50 & 0.50 & 0.58 & 0.56 \\
$\mathbf{2}$ & $\begin{array}{c}\text { Parametric } \\
\text { profile index } \\
\text { (IPP) }\end{array}$ & 6.36 & $6, .01$ & 7.18 & 5.80 & 5.46 \\
$\mathbf{3}$ & $\begin{array}{c}\text { Good } \\
\text { compression } \\
\text { index }\end{array}$ & 6.06 & 5.72 & 6.83 & 5.52 & 5.20 \\
\hline
\end{tabular}

\section{Loss on drying (\%HR)}

The powder was dried in a convection oven at $105^{\circ} \mathrm{C} \pm 2{ }^{\circ} \mathrm{C}$ until a constant weight was obtained 9.

\section{Hygroscopicity (\%H)}

The hygroscopicity determined by calculate the increase in sample weight after being kept in a humidifier 9.

\section{Percentage of particles measuring}

The particle size was calculated by means of a test such as a strainer and then observed a powder that passed through a sieve with a size of $0.05 \mathrm{~mm} 9$.

\section{Homogeneity index (It)}

Homogeneity index is used to determine particle size using filter test. The measurement of the $100 \mathrm{~g}$ powder is shaken for 10 minutes. The filter size used is: $0.355,0.212,0.100$ and $0.05 \mathrm{~mm} 9$.

Parameter Index (IP) defined as the limit that can be accepeted for indexes to detemine if the product is suitable to be processed by direct compression. IP calculated using this formula:
Parameter Index $(\mathrm{IP})=\left(\mathrm{n}^{\wedge} \mathrm{O} P \geq 5\right) /\left(\mathrm{n}^{\wedge} \mathrm{O} \mathrm{Pt}\right)$

Where :

$\mathrm{N} 0 \mathrm{P} \geq 5=$ the number of parameters where the value is equal to or higher than 5

$\mathrm{NOPt}=$ the total number of parameter that being studied.

The acceptability limit of IP should meet the value of 0,5 .

Parameter Profile Index (IPP) defined as the average ( $r$ ) of all parameters, or the value of the parameters calculated. The acceptability limit of IPP (r) should meet the value of 5 .

Good Compressibility Index (IGC) Formula = IPP x f

Where :

$\mathrm{f}=$ Reliability factor $=($ Polygon area $) /($ Circle area $)$

The reliability factor (f) explain that the more parameters included means the increasing of reliability of the method. The acceptability limit of IGC should meet the value of 5 .

Lactose $\mathrm{SD}$ is the choice of excipient for masking poor flow property of drug substances. SeDeM method helps to predict the aptitude of 
excipients to obtain orodispersible tablets and their suitability for direct compression and based on the result lactose SD is recommended to be used in the formulation.

\section{Application of SeDem System}

SeDeM system has numerous application. It could be applied to determine whether an API is suitabile to be manufactured by direct compression technology, based on the profile of SeDem diagram. Furthermore, this method could be applied to characterize an active pharmaceutical ingredient in powder form, and quality control of batches of a single API and excipient used in direct compression method 2 .

Table 2. Three parameters of disgregability in SeDeM ODT system.

\begin{tabular}{cccc}
\hline Factors & Parameter & $\begin{array}{c}\text { Limit value } \\
\text { (Minute) }\end{array}$ & Radius \\
\hline \multirow{2}{*}{ Disgregability } & Effervescence & $0-5$ (minutes) & $10-0$ \\
& $\begin{array}{c}\text { Disintegration Time with disk } \\
\text { (DCD) }\end{array}$ & $0-3$ (minutes) & $10-0$ \\
& Disintegration Time without disc & $0-3$ (minutes) & $10-0$ \\
\hline
\end{tabular}

Beside that, SeDeM system could be used to determine the amount of excipient required for the compression of an API that is not suitable for direct compression method2.

There are 12 parameters that measured in the SeDeM method system. To meet the qualification or acceptance of formulation for direct compression, the parametric index for the formula were interpreted in the form of numerical results of the radius ( $r$ ) and then described in a diagram called SeDeM Diagram. The parametric profile value for the results of the radius should be more than 5 . This value means that material is suitable for direct compression method2.

The SeDeM system is also used to prove the reproducibility of manufacturing between batches of the same powdered raw material. The utilization of SeDeM Diagrams in each batch can measure the degree of similarity or difference between the same API based on established parameters thus can determine its worthiness for direct compression method2.

SeDeM method is also applied to differentiate the excipient in the same chemical group and same functional type, but different in physical characteristics. The physical characteristics of an API for direct compression will determine their use in a drug formulation2.

There is a new model of SeDeM system, called SeDeM-ODT. This method used for developing tablet by direct compression method that can orally disintegrate (orally disintegration tablet, ODT). SeDeM-ODT can provides the Index of Good Compressibility \& Bucodispersibility (IGCB index) acquired from the previous SeDeM method. SeDeM-ODT model which has IGCB index concist of 6 factors. The index simultanously indicates if these tablets are suitable as bucodispersible tablet which can be disintegrated in $<3$ minutes. There is new factor, disgregability has 3 parameters that impact the parameter 2 .

In the past decade, the focus of interest is to develop the ODTs by trying different solutions to improve the formulation. Therefore, some excipient manufacturers started producing "superdisintegrants" which can be effectivelly used to reach the ODT's parameters. Moreover, there are many known techniques and methods that used to prepare such pharmaceutical forms, such as freeze-drying, molding, lyophilization and direct compression 11 . 
Direct compression is the most used method to manufacture ODTs. This method has a high efficiency and great variety of excipients and tablet manufacturing. The most critical step of ODT formulation process is the selection of superdisintegrant and determination of its concentration12. So, the advantage of SeDeM and SeDeM-ODT are it is efficient in terms of time and cost effective for both preformulation and formulation stage.

\section{Conclusion}

SeDeM system method could be used as a tools for knowing the parameters of materials for preformulations. By measuring the 12 parameters offered in the SeDeM system method, it can identify the most suitable excipient, calculate the maximum quantity of excipient that required in direct compression of API which is having poor flow, provide formulation with the minimum quantity of excipients so the use of unnecessary excipients such as binders, agglutinants and diluents could be avoided. This system can also be used as a quality control tool to study the reproducibility between batchs of API and excipients, based on the 12 parameters offered in the SeDeM Diagram.

\section{References}

York, P. 1992. Crystal engineering and particle design for the powder compaction process. Drug Dev Ind Pharm, Vol. 18 (6,7) : 677-721.

Bhavsar, Bhatt B, Oza C, Trived S i, Sha S . 2015. A Review On: SeDeM Expert System in Formulation Development of Pharmaceutical Forms. JPSBR: Vol. 5 (4) : 363-369.

Josep M, Negre S, Lozano PP, Minarro M, Roig M. 2008. Application of the SeDeM diagram and a new mathematical equation in the design of direct compression tablet formulation. Eur J Pharm Biopharm, Vol. 69 (3) : 1029-1039.
Diaz JEA, Montoyo EG, Lozano PP, Negre S, Minarro M, Tico JR. 2009. The use of SeDeM Diagram expert system to determine the suitability of diluents- disinte-grants for direct compression and their use in formulation of ODT. Eur J Pharm Biopharm, Vol. 73 : 414423.

Montserrat M, Pilar P, Josep MS, Manel R, Roser F, Encarna G, et al. 2006. A new expert system (SeDeM Diagram) for control btach powder formulation and preformulation drug product. Eur J Pharm Biopharm, Vol. 64 : 351-359.

Josep M, Sune Negre. 2011. SeDeM diagram: a new expert system for the formulation of drugs in solid form. Expert system for human, material and atomization (Intech) : 17-34.

Inderbir S， Pradeep K. 2012. Preformulation studies for direct compression suitability of cefuroxime axetil and paracetamol: a graphical representation using sedem diagram. Acta Pol Pharm, Vol. 69 : 8793.

Pawar H, Varkhade C, Jadhav P, and Mehra K. 2014. Development and evaluation of orodispersible tablets using a natural polysaccharide isolated from Cassia tora seeds. Integrative Medicine Research : 1-28.

Tadwee I, Shahi S, Zaheer Z. 2017. Preformulation Studies Using Lactose In Development Of Solid Oral Dosage Form: A Graphical Representation Using Sedem Method. International Journal of Current Pharmaceutical Research, Vol. 9 (5).

Aguilar DJE, García ME, Pérez LP, Sune NJM, Minarro M and Tico JR. 2011. Contribution to development of ODT using an innovator tool: SeDeM-ODT. Proceedings of X Congreso de la Sociedad Española de Farmacia. Madrid : Industrial Galénica.

Zajicek MJF, JS Barrett, JH Worthington, et al. 2013. A report from the 
pediatric formulations task force: perspectives on the state of child-friendly oral dosage forms. The AAPS Journal 15.
Nayak AK. and K. Manna. 2011. Current developments in orally disintegrating tablet technology. J. Pharm. Educ. Res., Vol. 2 : 2134. 